\title{
THE EFFECTS OF BROMAZEPAM ON THE EARLY STAGE OF VISUAL INFORMATION PROCESSING (P100)
}

\author{
Fernanda Puga', Isabel Sampaio², Heloisa Veiga', Camila Ferreira², \\ Maurício Cagy33, Roberto Piedade ${ }^{4}$, Pedro Ribeiro ${ }^{5}$
}

\begin{abstract}
The early stages of visual information processing, involving the detection and perception of simple visual stimuli, have been demonstrated to be sensitive to psychotropic agents. The present study investigated the effects of an acute dose of bromazepam (3 mg), compared with placebo, on the P100 component of the visual evoked potential and reaction time. The sample, consisting of 14 healthy subjects ( 6 male and 8 female), was submitted to a visual discrimination task, which employed the "oddball" paradigm. Results suggest that bromazepam ( $3 \mathrm{mg}$ ) impairs the initial stage of visual information processing, as observed by an increase in P10o latency.
\end{abstract}

KEY WORDS: bromazepam, visual evoked potential, P100.

\begin{abstract}
Efeitos do bromazepam no estágio inicial do processamento de informação visual (P100)
RESUMO - Os estágios iniciais do processamento da informação visual, envolvendo a percepção e detecção de um estímulo visual simples, tem demonstrado serem sensíveis a agentes psicotrópicos. O presente estudo investigou os efeitos de uma dose aguda de bromazepam (3 mg), comparado com placebo, no componente P10o do potencial evocado visual e no tempo de reação. A mostra consistiu de 14 sujeitos sadios ( 6 homens e 8 mulheres), submetidos a uma tarefa de discriminação visual, a qual empregou o paradigma "oddball". Os resultados sugerem que o bromazepam (3 $\mathrm{mg}$ ) prejudica o estágio inicial do processamento da informação visual, como observado pelo aumento da latência do P100.
\end{abstract}

PALAVRAS-CHAVE: bromazepam, potencial evocado visual, P100.

Benzodiazepines, such as bromazepam, have been therapeutically used due to their sedative, hypnotic, muscle relaxant, anxiolytic, and anticonvulsivant properties'. Their mechanism of action on the central nervous system (CNS) is believed to be related to the ability to enhance the activity of the gamma aminobutyric acid (GABA), the major inhibitory neurotransmitter ${ }^{2-4}$. Studies employing EEG parameters have demonstrated that bromazepam impairs a variety of neuropsychological functions such as memory, attention, psychomotor activity, reaction time, and vigilance performance $\mathrm{e}^{5-8}$. Specifically, event-related potentials (ERPs), such as the P100, N200, P300 and $\mathrm{N} 400$, have been widely employed in the evaluation of the distinct stages of information processing and in the identification of changes in neural activation yielded by distinct drugs ${ }^{9-11}$.
The occipitally distributed P100 component, in particular, is associated with the nerve conduction velocity of visual inputs from the retina to the primary visual cortex and, therefore, is related to the early stages of information processing, especially those involving the detection of simple stimuli and perceptual categorization of different stimulus modalities ${ }^{12}$. In this sense, the P10o has been extensively employed to characterize sensory-perceptual processes, such as somatosensory awareneness, facial recognition, and visuospatial attention ${ }^{13-15}$. Given that early stages of information processing are sensitive to pharmacological agents ${ }^{16,17}, P_{100}$ analyses enable a meaningful understanding of how a specific substance influences CNS ability to process incoming information. However, despite the vast number of studies employing ERP measures to understand changes in neuronal in-

\footnotetext{
'Mestre em Saúde Mental, Laboratório de Mapeamento Cerebral e Integração Sensório-Motora, Instituto de Psiquiatria (IPUB), Universidade Federal do Rio de Janeiro, Rio de Janeiro RJ, Brazil (UFRJ); ${ }^{2}$ Mestranda, Laboratório de Mapeamento Cerebral e Integração Sensório-Motora, IPUB/UFRJ; ${ }^{3}$ D.Sc. Engenharia Biomédica, COPPE, UFRJ; 'Professor Adjunto III Doutor, Coordenador do Laboratório de Mapeamento Cerebral e Integração Sensório-Motora, IPUB/UFRJ; ${ }^{5}$ Professor Adjunto II PhD, Escola de Educação Física e Desportos (EEFD), Laboratório de Mapeamento Cerebral e Integração Sensório-Motora, IPUB/UFRJ, Professor Pesquisador, Universidade Castelo Branco (PROCIMH-UCB).
}

Received 24 October 2006, received in final form 25 June 2007. Accepted 11 August 2007.

Dra. Fernanda Patrício Puga - Instituto de Psiquiatria / Laboratório de Mapeamento Cerebral e Integração Sensório-Motora / Universidade Federal do Rio de Janeiro - Avenida Venceslau Brás 71 / Fundos - 22290-140 Rio de Janeiro RJ - Brasil. E-mail: fernandapuga@globo.com 
formation processing induced by psychotropic drugs, few have combined the P10o component and bromazepam. In a previous study, Puga et al..$^{18}$ analyzed the effects of bromazepam ( $3 \mathrm{mg}$ ) on the $\mathrm{P}_{300} \mathrm{com}$ ponent of the visual ERP (latency and amplitude), and on behavioral measures (Stroop, digit span, and reaction time). However, bromazepam did not produce any evident effects on the measures analyzed.

In this context, the present study aimed at complementing this first study by investigating if the intake of the same dose of bromazepam would produce any changes on the initial stage of visual information processing, through the P100 component of the visual evoked potential (VEP).

\section{METHOD}

The sample consisted of 14 volunteers, 6 male and 8 female, with ages varying between 21 and 38 years $(26 \pm 4$ years). All subjects were healthy, and did not use medication or any psychoactive or psychotropic substance at the time of the test. In order to increase group homogeneity, only righthanded subjects were included in the sample. To assure that subjects did not have any physical or mental health impairment, and to identify and exclude from the experiment any subjects who could contaminate future results, all participants were evaluated by a neuropsychiatrist. A questionnaire was developed and administered at the beginning of each test session to identify possible ERP biological determinants, such as food intake, body temperature, fatigue, drugs, among others. Subjects signed a consent form, where the experimental condition was thoroughly described. The experiment was approved to the Psychiatric Institute's ethics committee.

Subjects received a capsule (bromazepam or glucose) on two separate days, under a randomized, double-blind, crossover study. The procedures were presented in the following routine: 1) First visual evoked potential; 2) Administration of a capsule (bromazepam 3 mg, or placebo); 3) The second visual evoked potential, 20 minutes after capsule ingestion; 4) The third visual evoked potential, 6o minutes after capsule ingestion.

Visual evoked potential: data acquisition and analysis A sound-attenuated room was prepared for data acquisition. Subjects were seated comfortably in a chair with armrest to minimize muscular artifacts. During the visual task, lights were turned off for subjects to concentrate exclusively on the monitor screen. A 15" Samsung monitor was placed in front of the individual. The visual stimulus was presented on the monitor by the ERP acquisition software, developed in DELPHI 5.0. To elicit the P100, all subjects were administered the same visual discrimination task, which employed the "oddball" paradigm. In this paradigm, two stimuli are presented randomly, with one occurring infrequently ${ }^{19}$. The subjects were asked to discriminate the target (infrequent) from the non-target or standard stimuli (frequent). In the present experiment, target stimuli were represented by a square and non-target, by a circle. Subjects were instructed to respond to the target stimulus by pressing a button mounted on a joystick (Model Quick Shot-Crystal CS4281) with their right index finger. Individuals' reaction time was measured at each trial. Each subject received one block of stimulus presentation. In each block, there was a $95 \%$ chance of 1 to 4 non-target stimuli preceding a target stimulus and a $5 \%$ chance of 5 to 7 non-target stimuli preceding a target stimulus. Specifically, 100 target stimuli were always presented in each block. The total number of stimuli presented, targets plus non-targets, varied between 350 and 400 in each block. The stimulus appeared on the screen for 0.75 seconds with and inter-trial interval (onset to onset) of 1.5 seconds.

The International $10 / 20$ System $^{20}$ for electrode placement (referred to linked earlobes) was used with a 20-channel Braintech-3000 (EMSA-Medical Instruments, Brazil). The 20 monopolar electrodes were arranged in a nylon cap (Electro Cap Inc., Fairfax, VA, USA). Impedance for EEG and EOG electrodes were under $5 \mathrm{~K} \Omega$ and $20 \mathrm{~K} \Omega$, respectively. Visual inspection was employed for detection and elimination of artifacts. The EEG data acquired had total amplitude of less than $100 \mu \mathrm{V}$. The signal was amplified with a gain of 22,000. Eye-movement (EOG) artifact was monitored with a bipolar electrode montage using two 9-mm diameter electrodes attached above and on the external canthus of the right eye. Moreover, independent component analysis (ICA) was applied to remove possible sources of artifacts ${ }^{21}$. The EEG signal was analog filtered between $0.16 \mathrm{~Hz}$ (high-pass) and $35 \mathrm{~Hz}$ (low-pass), and sampled at $240 \mathrm{~Hz}$. The software ERP Acquisition (Delphi 5.0), developed at the Brain Mapping and Sensorimotor Integration Lab, was employed with a $60 \mathrm{~Hz}$ notch.

Filter and epoch selection routines were used to process acquired digital data. After data were acquired and stored, the averaging software loaded the data and established different routines. The target stimulus (square) was selected as the trigger-stimulus. Epochs (i.e., visualization windows) were set to begin $120 \mathrm{~ms}$ pre-stimulus onset through 700 ms post-stimulus. After specific channels were selected ( $\mathrm{O}_{1}$, $\mathrm{Oz}$ and $\mathrm{O}_{2}$ ), data were averaged and represented graphically in terms of latency (x-axis) and amplitude (y-axis). Epochs related to target stimuli were considered and averaged only when subjects responded between 150 and 1000 ms. The P100 component was identified as a positive component within the latency window of 50-150 ms. Amplitude was measured at peak latency and relative to a pre-stimulus baseline of $120 \mathrm{~ms}$. Peak latency was defined as the time point of maximum positive amplitude within the specific latency window.

Reaction time - Volunteers responded to the target stimulus by pressing a button in a joystick. Although reaction time is not directly related to ERP measures, it was used to verify subjects' alertness during the task and as an index of individuals' motor performance in the oddball task. The joystick was used to measure individuals' reaction time at each trial. Missed stimuli were not considered. 
Statistical analysis - For reaction time, a two-way ANOVA, drug condition $x$ time point $(2 \times 3)$, was applied. For the electrophysiological variables, latency and amplitude (target $\mathrm{P} 100)$, a three-way ANOVA, drug condition $x$ time point $x$ electrode $(2 \times 3 \times 3)$ was performed. A post hoc (Scheffé) was applied a posteriori. The experimental drug conditions were defined as: bromazepam and placebo. Experimental time points were $o^{\prime}$ (baseline), 20', and 6o' after capsule ingestion. The electrodes analyzed were $\mathrm{O}_{1}, \mathrm{Oz}_{1}$ and $\mathrm{O}_{2}$.

\section{RESULTS}

Behavioral - Figure 1 expresses the variation in mean reaction time (oddball task) across the two established drug conditions (bromazepam and placebo) and time points $\left(0^{\prime}, 20^{\prime}, 60^{\prime}\right)$. The reaction time variable refers exclusively to the correctly detected targets. No main time point effect $F(2,81)=0.41 ; \mathrm{p}=$ 0.661 or drug condition effect $F(1,82)=0.09 ; \mathrm{p}=0.927$ were found. No interaction was observed $F(2,168)=$ $0.845 ; p=0.434$.

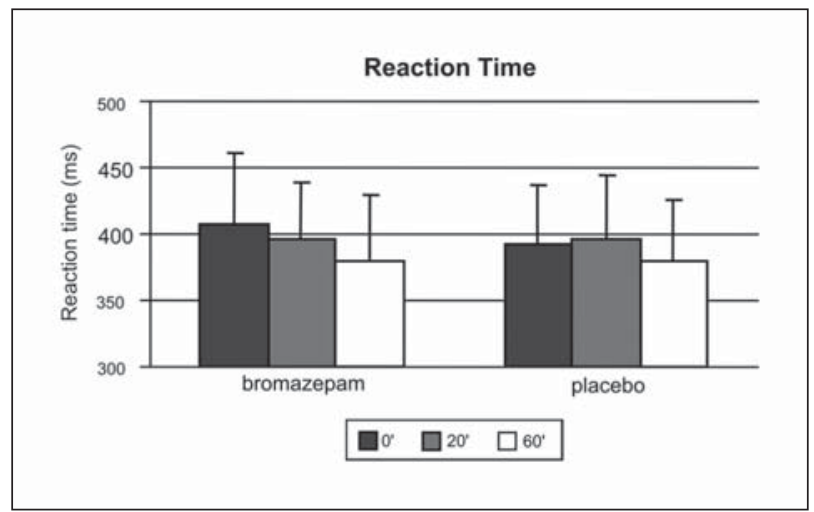

Fig 1. Reaction time mean score variation across experimental drug conditions (bromazepam and placebo) and time points $\left(0^{\prime}, 20^{\prime}\right.$, and $\left.60^{\prime}\right)$.

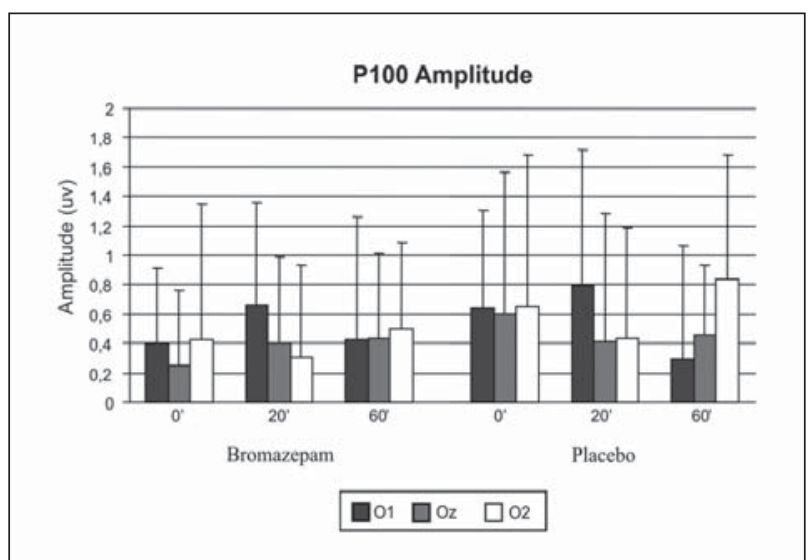

Fig 3 - P100 amplitude (mean / std. error) across drug conditions (bromazepam and placebo) and time points ( $0^{\prime}, 20^{\prime}$, and 60'), in $\mathrm{O}_{1}, \mathrm{Oz}_{2} \mathrm{O}_{2}$ electrode sites.
Electrophysiological - Figure 2 illustrates P100 latency variations across drug conditions, and time points, at the $\mathrm{O}_{1}, \mathrm{Oz}_{2}$, and $\mathrm{O}_{2}$ electrode sites. The three-way ANOVA revealed a main effect of drug condition $F(1,250)=23.87 ; \mathrm{p}=0.000$. Specifically, a significant increase in latency was observed in the bromazepam condition when compared to the placebo. The analysis also revealed main effect of time point $F(2,249)=3.38 ; \mathrm{p}=0.036$, characterized by an increase across time points. The post hoc analysis indicated a significant difference between $o^{\prime}$ and $6 o^{\prime} p=0.037$. No main effect of electrode was found $F(2,249)=0.03$; $\mathrm{p}=0.969$. The analysis also pointed out to an interaction between drug condition and time point $F\left(\mathbf{2}_{\text {, }}\right.$ 504) $=18.65 ; p=0.000$. In this sense, results show a constant increase in latency values across time points, which was more evident in the bromazepam group.

Figure 3 illustrates $P_{100}$ amplitude variations across the same drug conditions, time points, and

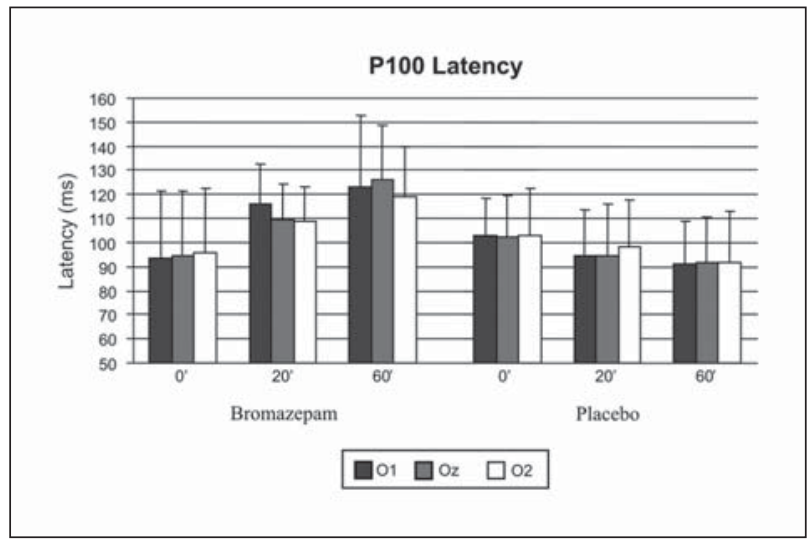

Fig 2. P10o latency (mean / std. error) across drug conditions (bromazepam and placebo) and time points $\left(0^{\prime}, 20^{\prime}\right.$, and $\left.60^{\prime}\right)$, in $\mathrm{O}_{1}, \mathrm{O}_{2}, \mathrm{O}_{2}$ electrode sites.

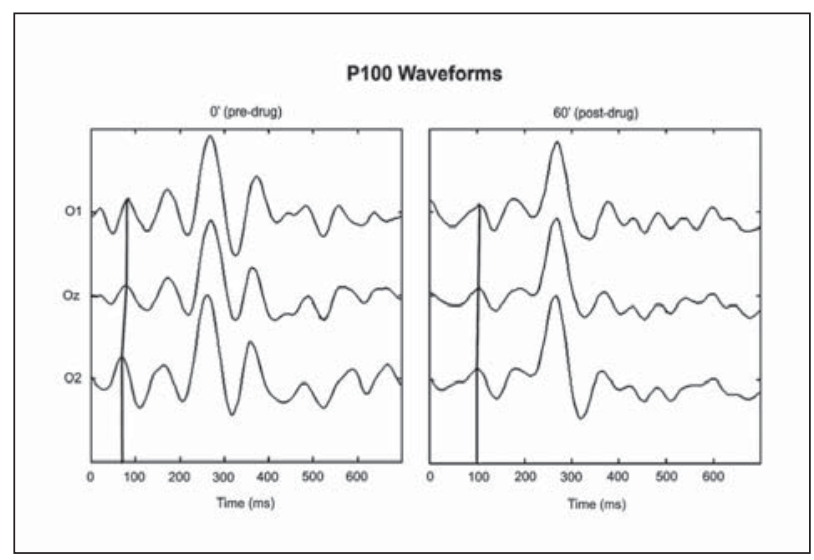

Fig 4. P10o waveforms at $\mathrm{O}_{1}, \mathrm{Oz}$ and $\mathrm{O}_{2}$ electrode sites and at $o^{\prime}$ and $6 o^{\prime}$ time points. 
electrode sites. The ANOVA revealed no main effects of drug condition $F(1,250)=2.44 ; \mathrm{p}=0.120$, time point $F(2,249)=0.00 ; \mathrm{p}=0.997$, or electrode site $F(2,249)=$ $0.50 ; p=0.605$. No interactions were observed. Even though the differences were not statistically significant, $P_{100}$ amplitude tended to be smaller in the bromazepam condition when compared to the placebo.

Figure 4 shows $\mathrm{P} 100$ waveforms at different electrode sites and at pre and post-drug time-points ( $o^{\prime}$ and $\left.60^{\prime}\right)$, where latency differences were statistically significant.

\section{DISCUSSION}

The present study aimed at investigating the effects of bromazepam (3 $\mathrm{mg}$ ) through behavioral and electrophysiological variables. The results were compared among conditions (placebo and bromazepam), time points (before, 20 and 60 minutes after drug intake) and cortical areas $\left(\mathrm{O}_{1}, \mathrm{Oz}_{2}\right.$ and $\left.\mathrm{O}_{2}\right)$. The following discussion will be divided into two dependent variables, which were used to assess the effects of drug intervention: a) reaction time and b) P100 (latency and amplitude).

Reaction time - Reaction time was used to verify subjects' alertness during the task and to analyze stimulus recognition, motor response, and sensorimotor performance. In the present study, the effects of a single oral dose of bromazepam ( $3 \mathrm{mg}$ ) and placebo were observed before, 20' and 60' after drug ingestion. The statistical analysis did not indicate any drug condition or time point main effects. Some studies have analyzed the effects of bromazepam on reaction time. Jansen et al. examined the effects of bromazepam ( $6 \mathrm{mg}$ and $12 \mathrm{mg}$ ) on reaction time sixty-five minutes after drug administration, and observed decreased performance ${ }^{6}$. Bourin et al. investigated the effects of bromazepam (3 $\mathrm{mg}$ ) and other benzodiazepines on twenty healthy volunteers. Bromazepam effects were evaluated 2 and 6 hours after administration and no significant difference was shown 2 hours after drug ingestion. However, a longer motor reaction time was observed 6 hours after bromazepam ingestion 7 . In another study, Hobi et al. observed a lengthening of reaction time for all three groups (placebo, bromazepam 1.5mg and bromazepam 3mg), but concluded that this result was due to the type of experimental design used, and only slightly to the drug's action ${ }^{22}$.

Considering the results of the studies cited above, it can be concluded that the results may be influenced by the methodological factors such as the dosage administrated, the task employed, and time after drug administration that reaction time was measured. It may be possible that reaction time is not a sensitive measure to detect drug effects on the conditions described in the experiment.

$P_{100}$ - It is speculated that detriments to the $P_{100}$ might compromise other components ( $\mathrm{P}_{3} 00$ and $\mathrm{N} 400$, for example), either by decreasing amplitudes and/or increasing latency values. Thus, the integrity of information processing seems to be dependent on the reliability of early visual inputs ${ }^{23}$. Given that impairment of these inputs may underlie the failure of high-level processes, such as attention, memory and sensorimotor performance, and once the P100 has been demonstrated to be sensitive to pharmacological agents, the understanding of the effects of specific drugs on the initial stages of information processing becomes imperative.

To elucidate this issue, the present experiment addressed the modulatory effects of bromazepam on the P100 using the "oddball" paradigm. We expected to find longer latencies and lower amplitudes in the bromazepam condition due to the drug's GABA enhancement property. In other words, we expected to see an impairment of the early stage of information processing after drug intake. The results partially confirmed this hypothesis. A noted increase in latency values was observed after bromazepam ingestion, showing that a single oral dose of bromazepam (3 $\mathrm{mg}$ ) can modify the time of synaptic conduction on this early stage of visual information processing. Therefore, the statistically significant increase in P100 latency values across time points in the bromazepam group can be understood as a result of the GABAergic effect of the drug, which increases the inhibitory postsynaptic potential (IPSP) on the visual cortex.

However, in relation to amplitude values, only a trend of decrease was seen. The absence of statistically significant differences for amplitude values might have been caused by other factors, such as the dosage employed, methodological aspects and the anxiety level of the subjects. Hence, a single bromazepam dose of $3 \mathrm{mg}$ seems to directly interfere on the speed of information processing (latency), but not on the allocation of attentional resources during the given task (amplitude).

As stated previously, few studies have associated P100 variability with the administration of benzodiazepines. Recently, Pompéia et al. ${ }^{17}$ investigated specific changes in visual perception produced by two different substances. They observed that P10o latency increased after lorazepam (2.0 $\mathrm{mg}$ ) and flunitrazepam 
(1.2 mg) intake when compared to a placebo group. No significant changes were observed for $\mathrm{P}_{100} \mathrm{am}$ plitude. In another study, van Leeuwen et al. ${ }^{24}$ evaluated the effects of two acute doses of oxazepam (20 and $40 \mathrm{mg}$ ) on the vigilance performance of 18 male subjects. The amplitudes of distinct PEV components $\left(P_{1}, N_{1}, P_{2} N_{2}\right.$ and $\left.P_{3}\right)$ were analyzed. Results indicated that the drug reduced the amplitudes of all ERP waves. The authors concluded that oxazepam impairs all aspects of information processing, as manifested in the various ERP waves, suggesting a state of general sedation. The authors also argued that the $\mathrm{P}_{100}$ may, to some extent, be considered endogenous once effects of task manipulation and attention were observed in a time window between 28 and $100 \mathrm{~ms}$. Rockstroh et al. ${ }^{16}$, in a different study, analyzed the effects of gradually increasing doses of clonazepam on 36 male volunteers submitted to a VEP task using a checkerboard reversal procedure. P100 amplitude reduced in the clonazepam condition when compared to the placebo. Latency did not significantly differentiate treatment groups. In this context, the results of the present study are in accordance with the literature. It appears that performance impairment produced by a benzodiazepine may be reflected by alteration either in amplitude values, latency or both. It must be stressed that the different methodologies used in these studies may account for the different results reached by each group.

\section{REFERENCES}

1. Lucchesi LM, Pompéia S, Manzano GM, et al. Flunitrazepam-induced changes in neurophysiological, behavioral, and subjective measures used to asses sedation. Progr Neuropsychopharmacol Biol Psychiatry 2003;27:525-533.

2. Katzung BG. Basic clinical pharmacology. 6. Ed. London: Pretence-Hall International, 1995

3. Oelschlager H. Chemical and pharmacologic aspects of benzodiazepines. Schweiz Rundsch Med Prax 1989;78:766-772.

4. Kopp C, Rudolph U, Low K, Tobler I. Modulation of rhythmic brain activity by diazepam: GABA(A) receptor subtype and state specificity. Proc Natl Acad Sci USA 2004;101:3674-3679.

5. Munte TF, Gehde E, Johannes S, Seewald M, Heinze HJ. Effects of alpra- zolam and bromazepam on visual search and verbal recognition memory in humans: a study with event-related brain potentials. Neuropsychobiology 1996;34:49-56.

6. Jansen AAI, Verbaten MN, Slangen JL. Acute effects of bromazepam on signal detection performance digit symbol substitution test and smooth pursuit eye movements. Neuropsychobiology 1988;20:91-95.

7. Bourin M, Auget JL, Colombel MC, Larousse C. Effects of single oral doses of bromazepam, buspirone and clobazam on performance tasks and memory. Neuropsychobiology 1989;22:141-145.

8. Koelega HS. Benzodiazepines and vigilance performance: a review. Psychopharmacology 1989;98:145-156.

9. van Leeuwen TH, Verbaten MN, Koelega HS, Kenemans JL, Slangen JL. Effects of bromazepam on single-trial event-related potentials in a visual vigilance task. Psychopharmacology 1992;106:555-564.

10. Pompéia S, Bueno OFA, Lucchesi LM, Manzano GM, Galduroz JCF, Tifik S. A double-dissociation of behavioral and event-related potential effects of two benzodiazepines with similar potencies. J Psychopharmacol 2000;14:288-298.

11. Anderer P, Saletu B, Semlitsch HV, Pascual-Marqui RD. Perceptual and cognitive event-related potentials in neuropsychopharmacology: methodological aspects and clinical applications (pharmaco-ERP topography and tomography). Methods Find Exp Clin Pharmacol 2002;24:121-137.

12. Kutas M, Iragui V, Hillyard SA. Effects of aging on event-related brain potentials (ERPs) in a visual detection task. Electroencephalogr Clin Neurophysiol 1994;92:126-139.

13. Taylor MJ. Non-spatial attentional effects on P1. Clin Neurophysiol 2002 113:1903-1908.

14. Herrmann MJ, Ehlis AC, Ellring H, Fallgatter AJ. Early stages (P100) of face perception in humans as measured with event-related potentials (ERPs). J Neural Transm 2005;112:1073-1081.

15. Eimer M, Forster B. Modulations of early ERP components by transient and sustained spatial attention. Exp Brain Res 2003;15:24-31.

16. Rockstroh B, Elbert T, Lutzenberger W, Altenmüller. Effects of the anticonvulsivant benzodiazepine clonazepam on event-related brain potentials in humans. Electroencephalogr Clin Neurophysiol 1999;78:142-149.

17. Pompéia S, Manzano GM, Galduróz JCF, Tufik S, Bueno OFA. Lorazepam induces an atypical dissociation of visual and auditory event-related potentials. J Psychopharmacol 2003;17:31-40.

18. Puga F, Veiga H, Cagy M, McDowell K, Piedade R, Ribeiro P. Analysis of the influence of bromazepam on cognitive performance through the visual evoked potential (P300). Arq Neuropsiquiatr 2005;63:228-234.

19. Polich J. P300 clinical utility and control of variability. J Clin Neurophysiol 1998;15:14-33.

20. Jasper H. The ten-twenty electrode system of the international federation. EEG Clin Neurophysiol 1958;10:371-375.

21. Delorme A, Makeig S. EEGLAB: an open source toolbox for analysis of single-trial EEG dynamics. J Neurosci Methods 2004;134:9-21.

22. Hobi V, Dubach UC, Skreta M, Forgo I, Riggenbach H. The subacute effect of bromazepam on psychomotor activity and subjective mood. J Int Med Res 1982;10:140-146.

23. Campanella S, Montedoro C, Streel E, Verbanck P, Rosier V. Early visual components (P100, N170) are disrupted in chronic schizophrenic patients: an event-related potentials study. Neurophysiol Clin 2006;36:71-78

24. van Leeuwen TH, Verbaten MN, Koelega HS, Slangen JL, van der Gugten J, Camfferman G. Effects of oxazepam on event-related brain potentials, EEG frequency bands, and vigilance performance. Psychopharmacology (Berl) 1995;122:244-262. 